\title{
BMJ Open Patients as partners in Enhanced Recovery After Surgery: A qualitative patient-led study
}

Chelsia Gillis, ${ }^{1}$ Marlyn Gill, ${ }^{2}$ Nancy Marlett, ${ }^{1,2}$ Gail MacKean, ${ }^{3}$ Kathy GermAnn, ${ }^{4}$ Loreen Gilmour, ${ }^{5}$ Gregg Nelson, ${ }^{6}$ Tracy Wasylak, ${ }^{7}$ Susan Nguyen, ${ }^{2}$ Edamil Araujo, ${ }^{2}$ Sandra Zelinsky, ${ }^{2}$ Leah Gramlich ${ }^{8}$

To cite: Gillis C, Gill M, Marlett N, et al. Patients as partners in Enhanced Recovery After Surgery: A qualitative patient-led study. BMJ Open 2017;7:e017002. doi:10.1136/ bmjopen-2017-017002

- Prepublication history for this paper is available online. To view these files please visit the journal online (http://dx.doi. org/10.1136/bmjopen-2017017002.

Received 27 March 2017 Revised 26 May 2017 Accepted 30 May 2017
CrossMark

For numbered affiliations see end of article.

Correspondence to Chelsia Gillis; chelsia.gillis@ ucalgary.ca

\section{ABSTRACT}

Objectives Explore the experience of patients undergoing colorectal surgery within an Enhanced Recovery After Surgery (ERAS) programme. Use these experiential data to inform the development of a framework to support ongoing, meaningful patient engagement in ERAS.

Design Qualitative patient-led study using focus groups and narrative interviews. Data were analysed iteratively using a Participatory Grounded Theory approach.

Setting Five tertiary care centres in Alberta, Canada, following the ERAS programme.

Participants Twenty-seven patients who had undergone colorectal surgery in the last 12 months were recruited through purposive sampling. Seven patients participated in a codesign focus group to set and prioritise the research direction. Narrative interviews were conducted with 20 patients.

Results Patients perceived that an ERAS programme should not be limited to the perioperative period, but should encompass the journey from diagnosis to recovery. Practical recommendations to improve the patient experience across the surgical continuum, and enhance patient engagement within ERAS included: (1) fully explain every protocol, and the purpose of the protocol, both before surgery and while in-hospital, so that patients can become knowledgeable partners in their recovery; (2) extend ERAS guidelines to the presurgery phase, so that patients can be ready emotionally, psychologically and physically for surgery; (3) extend ERAS guidelines to the recovery period at home to avoid stressful situations for patients and families; (4) consider activating a programme where experienced patients can provide peer support; (5) one size does not fit all; personalised adaptations within the standardised pathway are required. Drawing upon these data, and through consultation with ERAS Alberta stakeholders, the ERAS team developed a matrix to guide sustained patient involvement and action throughout the surgical care continuum at three levels: individual, unit and ERAS system.

Conclusion This patient-led study generated new insights into the needs of ERAS patients and informed the development of a framework to improve patient experiences and outcomes.

\section{INTRODUCTION}

The Enhanced Recovery After Surgery (ERAS) programme applies evidence-based

\section{Strengths and limitations of this study}

- This is the first patient-led ERAS (Enhanced Recovery After Surgery) study, where patients were trained to conduct experiential patient research, to characterise the needs and expectations of patients following ERAS care.

- Our qualitative findings emerged from participatory grounded theories: a methodology that involves patients as partners throughout the research process.

- Patient-led research provides an important link between experiential patient research and implementation, adding to the foundation of implementation science.

- We cannot assume that our findings regarding patients' experience with ERAS for colorectal surgery are representative of all patient experiences with ERAS.

perioperative interventions that, collectively, reduce morbidity and length of hospital stay. ${ }^{1-3}$ Given its clinical success, a number of qualitative studies have been conducted to provide insight into patient experiences and satisfaction with the programme. Overall, a high level of contentment with ERAS has been reported with the exception of a few services: preoperative preparation and postoperative support have been consistently documented as not meeting patient needs. ${ }^{4-7}$ Despite these qualitative findings, there has been little change in the pre and postoperative supportive guidelines.

Patient-centeredness is fundamental to the mission of healthcare, yet traditionally patients have not been involved as partners in shaping their health services. This issue is multifaceted and has real clinical consequences. For instance, central to ERAS' effectiveness is the adherence to 22 elements, ${ }^{8}$ some of which, such as preadmission oral carbohydrate loading, are completely reliant on patient adherence. A clearer understanding of the 
patient's perceived and potential role, as well as how to best support patients throughout their surgical journey, is an essential first step in mitigating potential patient barriers to successful ERAS implementation. Furthermore, understanding this experience from the patient perspective can highlight issues that health professionals and health systems may not anticipate.

The primary research objective was to explore the experience of patients undergoing colorectal surgery within an ERAS programme, in order to develop a better understanding of how the ERAS system currently supports patient needs. Although a number of qualitative studies have addressed patients' experience with ERAS, no studies have been driven by patients, working with patients. Trained patient researchers with relevant surgery experience can effectively engage patient-participants throughout the research process to ensure the findings are relevant and important to the users of ERAS. ${ }^{9}$

In an effort to move beyond the dissemination of our findings, the ERAS team employed patient engagement consultants to develop a patient engagement framework for ERAS; therefore, the research conducted also includes an implementation component, which will be presented as part of the study findings. Building capacity for sustained patient engagement within the existing ERAS system has the potential to impact medical decision making, care process across the continuum, the quality of research conducted, uptake of research findings, adherence to care guidelines and, ultimately, health outcomes. 1011

\section{METHODS}

Patient and Community Engagement Researchers (PaCERs) are patients who have been trained to conduct experiential qualitative research using Participatory Grounded Theory methodology for the purpose of transforming the role of the patient's health, healthcare and health research. ${ }^{9}{ }^{12}$ Participatory Grounded Theory merges participatory research methods with the principles of grounded theory. ${ }^{13} 14$ The PaCER methodology of Set, Collect, Reflect (figure 1) engages patient-participants as partners throughout every step of the research process for the purpose of developing testable theories based on real-world patient experience. Employing patient-researchers, who have undergone a similar experience to that of the patient-participants, facilitates an environment where participants can be comfortable uncovering the depths of their own experience, and may reduce the perceived power imbalance between researcher and interviewee..$^{1516}$

\section{Patients}

A total of 27 patients were enrolled between July 2015 and September 2016 through purposive sampling from five hospitals in Alberta, Canada, employing the ERAS Alberta Implementation Program for colorectal surgery. ${ }^{2}$ Ethics approval for the PaCER study was obtained by the Conjoint Research Ethics Board. Patients met inclusion criteria if they had been identified by their surgeons as participants in the ERAS programme, were $>18$ years of age and spoke English well enough to participate in a focus group or interview. All patients were provided with a Consent to Contact Form at their surgeon's office and/ or during their primary hospital admission for surgery. Interested, consented patients were then contacted by a PaCER researcher who provided further study details. Patients did not have a prior relationship with the PaCER research team, and were made aware of the study objective. Recruitment was conducted by telephone and separated into two phases to generate a sample representative of varied postoperative lengths and experiences. Phase $1(n=15)$ involved recruitment for one focus group $(n=7)$ and eight narrative interviews with patients who had undergone surgery in the previous 12 months. To reach saturation and test emerging themes, we carried out a second phase of recruitment, which consisted of 12 in-hospital interviews and seven follow-up interviews at 3 weeks postsurgery. The sample included 10 women and 17 men, aged 29-89 years. None of the patients withdrew from the study. All study participants signed an informed consent form prior to being interviewed or participating in a focus group.

\section{Set/codesign focus group}

The Set stage is the initial codesign phase of the PaCER methodology. ${ }^{9}$ A 5-hour focus group was held in a private space within the university, with seven patients

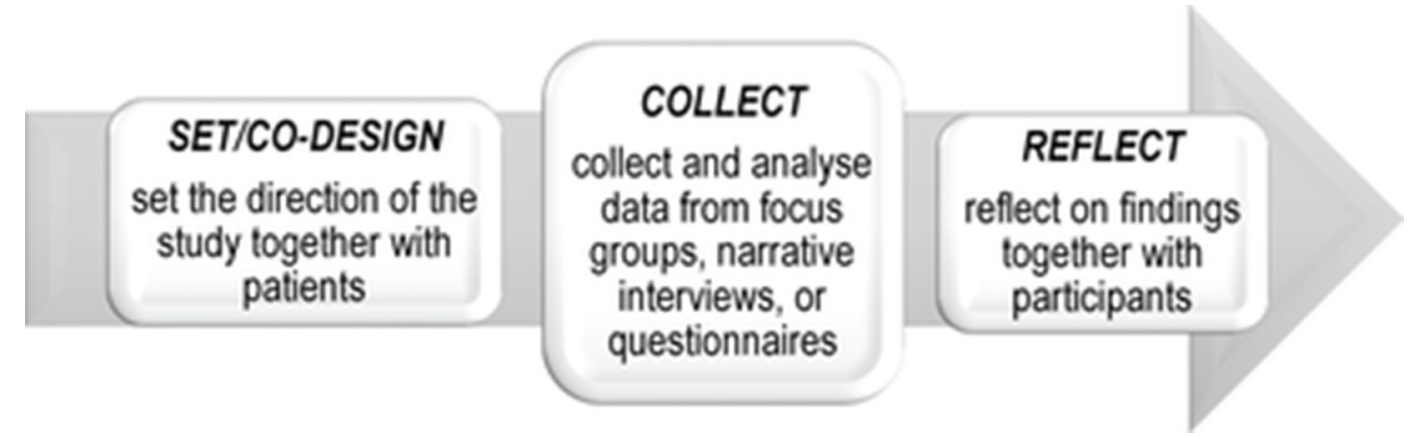

Figure 1 The PaCER (Patient and Community Engagement Research) methodology of Set, Collect, Reflect engages patientparticipants as partners throughout the research process. 
representing four hospitals, for the purpose of guiding data collection (ie, language and scope of responses). The initial question posed to the group was: Please tell us about your postsurgery experience while you were in hospital. This question opened the door for participants to describe their knowledge of ERAS and recount their experiences coping with the ERAS protocols. Discussion among the participants was encouraged with a series of prompts used by trained PaCER researchers to deepen and elaborate the information provided. The focus group was facilitated, audio recorded and transcribed by the PaCER researchers.

The topics that emerged included: (1) how nurses introduced and encouraged the ERAS protocols during the preoperative clinic education appointment and in-hospital; (2) presurgery stress; (3) surprise at the high level of gas pain; (4) stress around biopsy results; (5) nutrition; (6) level of knowledge of ERAS; (7) journals (an ERAS Alberta initiative to get patients to track compliance to ERAS elements not traditionally included in the ERAS programme or within patient charts). These initial ideas were shared with the ERAS teams and researchers and were used to formulate subsequent guiding questions for the data collection phase.

\section{Data collection/analysis cycles}

Data collection and analysis was conducted according to grounded theory practice, with small groups of interviews analysed by three PaCER researchers using open coding methods, in an iterative process to ensure interrogation of the data and emerging themes, as well as to guide the direction of recruitment and data collection strategies. ${ }^{9}$ All PaCER researchers kept a research diary to memo and be reflexive.

Narrative interviews encouraged participants to 'tell their story,' using prompts sparingly to elicit greater depth. Once the patients had told the story of their surgery experience, open-ended questions were posed to test emerging themes. Phase 1 included eight individual narrative interviews, in which five hospitals were represented. Phase 2 included participants from one hospital, in which 12 individual narrative interviews were conducted on the second postoperative day with seven follow-up interviews 3 weeks postdischarge. The interviews conducted at bedside were uninterrupted by non-participants. All interviews were conducted, audio recorded and transcribed by the PaCER researchers. After each interview and focus group, the participants reflected on what they had learnt about their experience and what they thought should be explored in future interviews. Data code saturation was reached after the 10th narrative interview. Data collection/analysis cycles with the PaCER team continued until a core construct emerged that organised the working theory and emerging themes. ${ }^{9}$

\section{Reflect}

Participants from the interview and codesign phases were invited to Reflect on the study findings. ${ }^{9}$ Interested participants $(n=7)$ engaged in a telephone interview to discuss the findings and offer feedback. This stage tests the truth value and consistency of the findings with the users of the ERAS programme.

The net result is a research method that involved patients as partners throughout the research process. The inclusion of patients in analysis and interpretation of findings ensures pragmatic and relevant recommendations. In fact, Participatory Grounded Theory has been used successfully to develop practice-changing theories to treat osteoarthritis and improve care in the intensive care unit. $^{1217}$

\section{Reliability}

Grounded theory methods ensure careful and ongoing interrogation of findings as data are collected and analysed. In addition, methods (two distinct methods, three phases of research) and data sources (five hospitals and in-patient, follow-up interviews) provided a foundation for triangulation of data to enhance the rigour of the study and breadth of study findings. ${ }^{18}$ Research colleagues in ERAS, academic PaCER supervisors and peers were also asked to review and discuss memos, emerging data, coding and themes to confirm the findings for the purpose of achieving investigator triangulation. Differences among researchers were discussed before coming to a consensus.

\section{RESULTS}

The core concept that emerged from the data was clear: the majority of patients, once they understood the ERAS programme, wanted to be included to know why the protocols were important and, most of all, wanted to take on an active, collaborative role throughout their surgical journey. By beginning this partnership early, patients feel better prepared to leave hospital and continue their recovery at home. Thus, the overarching concept is 'invite me into ERAS, from diagnosis to recovery, so that I can take responsibility for my own health.' Patients perceived that, to be a programme focused on enhanced recovery, ERAS should not be limited to the perioperative period, but should encompass the journey from diagnosis to recovery at home (figure 2). The Results section is therefore divided into four main categories, each with

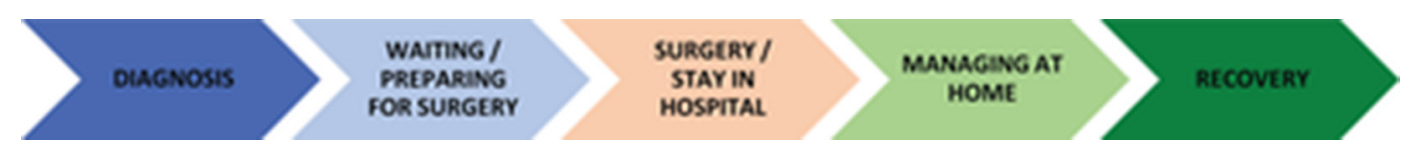

Figure 2 Patient-defined surgical journey. Patient-participants perceived that, to be a programme focused on enhanced recovery, the Enhanced Recovery After Surgery programme should not be limited to the perioperative period, but should encompass the journey from diagnosis to patient-defined recovery. 
Table 1 A patient-driven grounded theory of the ERAS journey

\begin{tabular}{|c|c|}
\hline \multicolumn{2}{|l|}{ Patient experiences with an ERAS programme } \\
\hline \multicolumn{2}{|c|}{$\begin{array}{l}\text { Overarching concept: invite me into ERAS, from diagnosis to recovery, so that I can take responsibility for my own } \\
\text { health }\end{array}$} \\
\hline Category & Subcategory \\
\hline $\begin{array}{l}\text { Waiting and preparing for surgery: preoperative } \\
\text { experiences }\end{array}$ & $\begin{array}{l}\text { Knowledge of ERAS } \\
\text { Preoperative information from surgeons and nurses } \\
\text { Stress: } \\
\text { Fears about surgery } \\
\text { Worry about finances, family, work } \\
\text { Bowel preparation and travel-related stressors } \\
\text { Lack of information }\end{array}$ \\
\hline $\begin{array}{l}\text { Surgery and stay in-hospital: in-hospital experiences with } \\
\text { providers }\end{array}$ & $\begin{array}{l}\text { Pain control } \\
\text { Journal } \\
\text { - Following ERAS protocol } \\
\text { - Medical care and postoperative health } \\
\text { - Rapport with providers }\end{array}$ \\
\hline $\begin{array}{l}\text { Surgery and stay in-hospital: non-provider-related in- } \\
\text { hospital experience }\end{array}$ & $\begin{array}{l}\text { Noise level } \\
\text { Nutrition }\end{array}$ \\
\hline $\begin{array}{l}\text { Managing at home: discharge and postdischarge } \\
\text { experiences }\end{array}$ & $\begin{array}{l}\text { Discharge information } \\
\text { Biopsy test results } \\
\text { Medical concerns and home help } \\
\text { Need for a designated contact }\end{array}$ \\
\hline
\end{tabular}

ERAS, Enhanced Recovery After Surgery.

subcategories: (1) patient preoperative experiences with seven subcategories; (2) in-hospital experiences with providers with five subcategories; (3) non-provider-related in-hospital experiences with two subcategories; (4) posthospital discharge experiences with four subcategories (table 1 ).

\section{Waiting and preparing for surgery: preoperative experiences Knowledge of ERAS}

More than half of patients interviewed did not know what ERAS was, or that they were involved in an ERAS programme. Many of the patients who were aware of ERAS, however, chose to become more informed prior to surgery and two participants chose to 'get themselves fit' for surgery.

\section{Preoperative information from surgeons and nurses}

Patients explained that nurses provided the majority of the ERAS information. Surgeons focused on the understanding of the surgical procedures and knowing what to expect when waking up postsurgery.

Many patients perceived that the preoperative information provided came too late.

'Of course, they did inform us about being fit but it was only 4 days before [surgery].'

'If somebody comes up to you and says "well, you should've went for walk for the first 3 weeks before your surgery' but you can't tell them that the day of the surgery you have to tell them that way beforehand. Any information you're going to get that's going to improve or speed up your recovery $99 \%$ of the people in the world are going to do it unless you physically can't.'

\section{Stress}

Many patients talked about various stressors they encountered while waiting for surgery, such as: (1) fears about the surgery; (2) worry about finances, family, work; (3) bowel preparation for those who had mobility issues or travel before surgery; and (4) lack of information.

In fact, almost all patients expressed some level of fear and believed that help resolving stressors, including guidance in the access of appropriate services, would have helped them during the waiting period for surgery, and allowed them to go into surgery much calmer and less tired. Patients believed that better presurgery physical and mental health equated to a faster recovery. Lack of knowledge of available resources meant few patients even reached out to community services on their own.

'There is a lot of stress and fear and those things can stop you getting well and healing fast. Should some thought be given to helping patients with stress and fears. Maybe there should be someone who can have a conversation with you so you can talk about all these things and make sure that you are in the best mind to be healed.'

Perceived lack of information regarding the results of preoperative assessments, what the surgeon had planned to do and how long it would take to recover from the surgery were all presurgery stressors. Of note, 
those who had attended a class or had been able to discuss their surgery with their surgeon or nurses felt more confident going into their surgery in knowing what to expect.

'.... Where the main thrust of learning about ERAS came was meeting the nurses [at the preoperative clinic] who were just godsends. I really look back fondly on that day.'

\section{Surgery and stay in-hospital: in-hospital experiences with providers}

Pain control

Most participants experienced some level of pain, especially during the first two postoperative days, but believed that providers controlled their pain level appropriately. A few patients had concerns about becoming addicted to the pain medication.

The pain that surprised many participants was the high level of intraperitoneal gas pain they experienced as a result of the inflation of the abdomen for laparoscopic surgery. These patients believed they should have been alerted to this possibility presurgery.

Patients treated with patient-controlled analgesia appeared to feel good about having some sense of control over their pain medication and were less anxious than patients who were relying on providers to administer the drugs. In fact, a few patients feared falling asleep in case their nurse forgot to bring the medication at the appropriate time.

\section{Journal}

In a novel approach with ERAS implementation and building on the McGill experience, Alberta Health Services adopted the use of journals for patients to track mobility, nutrition, breathing exercises, gum chewing and urinary output. Many patients who were given a journal to complete daily did not see the point of the journal and explained that they were too tired or too busy fulfilling the ERAS expectations to fill out all their journal activities. A few patients said it was helpful, but most felt it was not useful for them, and believed it was useful for the providers rather than patients.

'The nurses were motivating but I didn't want to write in the book, I got my mom or girlfriend to do it. Writing in the book was not my priority, walking around helps the bowels more.'

\section{Following ERAS protocols}

Patients who had a better understanding of the ERAS programme were more likely to follow the expected protocols. It would appear that fully understanding the rationale for the protocol led to greater adherence.

'I did it, but didn't know why. I think people would be more diligent if they knew why the walking was so important, why the protein was so important...'
Some patients perceived that they were too unwell to follow the programme, and explained that their providers were sticking to the protocol without taking their personal physical health into account. The inability of providers' to be flexible, or modify the ERAS protocols appeared to engender some anxiety around the protocols.

'The nurses and doctors were pushing me to eat. I did not understand how important it was to eat as soon as possible. I thought the body needs healing...'

Patients liked the concept of being part of a team that was invested in their timely recovery, rather than simply being told what to do. Being treated as an individual who was doing his/her best, and perceiving that providers were not simply following rules, allowed patients to invest more effort into following the protocols.

'...People want to help, and they want to have a sense of belonging, especially in the hospital where you're recovering and going through a tumultuous amount of thoughts... hey we're on this ERAS program, this is what we found helps other patients... and it would help if you did this...that partnership, that team.'

\section{Medical care and postoperative health}

Although most patients reported an uneventful recovery in hospital, several patients discussed concerns they had with their postoperative care, which caused undue anxiety and impeded recovery. These concerns included lack of information around biopsy results, inconsistency in information sharing between providers at shift changes, perceived mismanagement of nasogastric tubes and an inability to have a conversation with their surgeon.

\section{Rapport with providers}

Patients reported that good rapport or relationship with the nursing staff was provider dependent. Some nurses were really good at informing and supporting patients as individuals, others were less attentive or interested. Some nurses were perceived as being focused on following the ERAS protocols independent of the patient's condition.

\section{Surgery and stay in hospital: non-provider-related in- hospital experience \\ Noise level}

Most of the participants complained that the noise level in hospital made it difficult for them to sleep, even at night, and questioned whether this negatively impacted their recovery. Patients also wondered about the necessity of having blood samples taken in the middle of the night or very early in the morning.

\section{Nutrition}

Most patients stated that they would have preferred some guidance about appropriate food for relatives to bring from home. Patients who had been warned about the postoperative low-fibre diet of Alberta Health Services appeared more forgiving. A few patients noted that there 
were no food options available between scheduled mealtimes when they felt prepared to eat.

\section{Managing at home: discharge and postdischarge experiences \\ Discharge information}

Although the majority of patients believed they had adequate discharge information, some participants raised major concerns that had not been fully explained, including bleeding from the rectum, variation in bowel movements and diet. Mixed messages and differing provider advice also caused confusion for some patients. All of these issues caused varying levels of anxiety for patients' management at home.

'The surgery itself was actually a huge success but they didn't warn me about the number of accidents that I might have or things like that. From what I hear it is fairly common with a lot of people, and that wasn't discussed at all...'

'Don't feel that they gave me much information about what to expect [post op]. What is normal or not normal...I experienced a little bit of bleeding. I was kind of concerned about that. It took the nurse [surgeon's office] quite a while to get back to me on that too.'

'The take home sheet that I had, it did say eat more small meals and make sure you drink a lot of water. Things like that. Helpful hints. I wanted more detail than that.'

\section{Biopsy and test results}

Most patients did not receive their biopsy, or other test, results until their surgical consult 6 weeks after their operation. Many patients were unaware of the necessary time required to review and report these results, and this caused undue anxiety.

\section{Medical concerns and home help}

Several participants had medical concerns, such as problems with their incision, which caused anxiety, particularly because there was uncertainty regarding the best service to contact. The few participants who had needed and received help at home, believed that these providers had not received enough information from the hospital to be able to support them adequately.

\section{Need for a designated contact when patients go home}

Many patients believed it to be necessary to provide an alternate contact besides the surgeons, physicians or Health Link (24/7 telephone nurse advice and general health information for Albertans) to have their concerns addressed. Many hesitated to call their doctors' offices, especially about diet and bowel movements, and those who called because of concerns regarding their incision and bleeding usually waited up to 2 days to have their questions answered. There was consensus that either a professional or experienced patient volunteer, who could provide answers or knew where to direct their concerns, would be an ideal resource for patients managing their recovery at home.
'I do think that there should be a follow-up phone call about a week from that enhanced program itself, not just your doctor...how are things going, do you have any concerns, do you have any questions...'

\section{Implementation: a patient engagement framework}

Recognising that it is important to learn from patients' experience with ERAS, and use this learning to move research forward into practice, the ERAS team consulted patient engagement experts to develop a patient engagement framework. The approach taken to develop this framework was as follows:

- A scan of the academic literature regarding patient experiences with ERAS or other similar surgical programmes. A total of 11 articles were determined to be relevant, and reviewed (a comprehensive literature search and review was beyond the scope of this project). ${ }^{4519-27}$

- A scan of the grey literature regarding strategies for engaging surgery patients in quality improvement and for other patient engagement frameworks. ${ }^{28-31}$

- In-depth review of the present PaCER findings.

- Semistructured, key informant interviews $(n=9)$ were conducted with a purposive sample of four ERAS nurse coordinators, a PaCER researcher, a patient advisor from the provincial surgery governing body, a patient experience consultant for Alberta Health Services and a University of Calgary-based expert in patient-reported experience/outcome measures (PREM/PROM).

A continuum-based framework was developed based on the key guiding principles that emerged from the framework consultation (table 2) and on the International Association for Public Participation (IAP2) spectrum of participation. ${ }^{32}$ The framework involves patients selecting their desired level of ERAS involvement along a continuum of equally valued engagement options from we inform patients, patients inform us, patients 'co-lead' and 'co-design' with us, to patients lead at the level of being engaged in their own individual care, the unit care, and the ERAS system (table 3). The highest level of engagement involves patients as partners and researchers of ERAS. At this level, patients are meaningfully included as partners in the planning, conduct and dissemination of research. It is generally acknowledged that no part along this continuum is inherently 'better' than another part. ${ }^{30} 31$ Rather what's important is that there is a good match between how patients would like to be involved and the opportunities for involvement. Health professionals, organisations and patients can use this matrix to identify the extent of patient involvement, and what can be supported or sustained.

There is no value in collecting patient experience and outcome data unless it is going to be used to influence needed changes across the surgical continuum. ${ }^{11}$ At each level, there must be a mechanism to evaluate outcomes, and a mechanism to disseminate the findings 
Table 2 Key principles to guide patient engagement in ERAS

\section{Guiding principle}

1. 'One size will not fit all'

\section{Description}

No single step-by-step process or 'model' for patient engagement can be developed. There is a need to recognise the different cultures and contexts within which ERAS is being implemented; the reality that patients will have different preferences regarding how they want, or are able, to be involved at every level.

2. Wherever possible, build on existing mechanisms for capturing, analysing and disseminating patient/family feedback.

3. Experiences from a broad cross section of patients should be sought.

This approach will avoid unnecessary duplication of effort and will be more cost-effective. It is recognised, however, that new data collection, analysis and dissemination approaches may be required.

Patients with either very poor or very good experiences, and those with greater resources, are more likely to provide input. In order to capture a broad range of experiences, it is important to identify and address barriers to participation wherever possible.

4. Not all illnesses or surgeries are the same, so it may be important to identify subgroups of patients that may have some unique issues.

5. Priority should be given to what patients want to tell us, not just what the system wants to hear.

Although there will be some commonalities with respect to patients' experiences with colorectal surgery and ERAS, there may also be differences. For example, patients with inflammatory bowel disease may have some unique issues and needs compared with those with bowel cancer.

While ERAS personnel have many important questions about patient experiences, it is crucial that patients also have open-ended opportunities to talk about issues of importance to them, issues that may not be anticipated by health professionals.

6. Nursing units and the ERAS programme need to value patient feedback and expertise and be invested in ongoing learning and improvement.

7. Patients need to know how their input is being used.

Meaningful patient engagement requires that healthcare professionals be interested in hearing patient feedback and using it to inform changes in practice and policy. Individual health professionals need to be supported by units and facilities that are invested in and provide supports for ongoing learning and improvement.

Leading in, there is a need to let patients know how their input will be used, and then afterwards it is important to circle back and let patients know the impact of their input.

8. Patient engagement needs to be resourced if it is to be done well.
Patient insights can be a core contributor to changes in policy and practice that will result in more positive patient experiences and better outcomes. Patient engagement must be well resourced in order to optimise its value and contribution.

ERAS, Enhanced Recovery After Surgery.

and outcomes to the patients involved, local ERAS team, hospital and system leaders. Table 4 provides examples of a mechanism to evaluate and disseminate outcomes at the patient level.

\section{DISCUSSION}

The message that patients bring to ERAS is: if you tell us why, help us understand what we need to do, we will be happy to do all we can. The findings suggest that patients' perception that they play a major role within a collaborative ERAS team will improve patient experience and facilitate earlier recovery through a greater understanding and willingness to adhere to the ERAS in-hospital protocols, and through confidence in continuing their recovery after discharge. This improved confidence invites patients to cocreate with their ERAS team a patient-centred discharge/recovery plan, which should also reduce the postoperative burden (eg, readmissions).

A number of our patient findings, such as the desire for greater pre and postoperative information provision, have been reported previously, ${ }^{4-633}$ but have shown little to no change in the ERAS processes. This failure to implement evidence in practice might represent a gap in the Knowledge-to-Action Cycle. ${ }^{34}$

Our patient findings and the patient engagement framework provide ammunition to encourage the adoption of a strategy designed to improve patient experiences and outcomes, effectively closing the gap in the Knowledge-to-Action Cycle . Patient input is necessary if patient-centred care is to be operationalised ${ }^{35} 36$ and the patient engagement framework provides suggestions to include patients in a systematic process where patients are partners in ERAS. Implementation of the framework, thus, provides a means of moving research into practice, and could improve the patient-orientation of medical decision making, policy and future research within the ERAS system; ultimately, improving the ERAS processes so that the care provided matches patient values.

In addition, our findings highlight the importance of understanding patient experiences of ERAS in order to improve the experience for future patients. For example, recognition of numerous sources of anxiety as patients progress along the surgical continuum can inform development of strategies to address the emotional, 
Table 3 An 'engaging patients in ERAS' matrix

\begin{tabular}{|c|c|c|c|c|}
\hline & We inform patients & Patients inform us & $\begin{array}{l}\text { Patients 'co-lead' and } \\
\text { 'co-design' with us }\end{array}$ & Patients lead \\
\hline $\begin{array}{l}\text { Individual care level } \\
\text { (Patients are } \\
\text { engaged in their own } \\
\text { care) }\end{array}$ & $\begin{array}{l}\text { - Patients are provided with } \\
\text { clear information about } \\
\text { ERAS throughout the surgical } \\
\text { trajectory, in ways that work } \\
\text { for them. } \\
\text { - Preoperative education } \\
\text { information is shared with } \\
\text { patients prior to their clinic } \\
\text { appointment so that they can } \\
\text { ask informed questions. } \\
\text { - Information needs to be } \\
\text { repeated. }\end{array}$ & $\begin{array}{l}\text { - Patients tell us what's } \\
\text { important to them across } \\
\text { the surgical trajectory and } \\
\text { this information guides } \\
\text { their care. }\end{array}$ & $\begin{array}{l}\text { - Patients are } \\
\text { involved in shared } \\
\text { decision making. } \\
\text { - Patients are involved } \\
\text { in the development of } \\
\text { mechanisms, such as } \\
\text { apps or log books, to } \\
\text { track recovery. }\end{array}$ & $\begin{array}{l}\text { - Patients } \\
\text { make their own } \\
\text { decisions based } \\
\text { on information and } \\
\text { options provided. } \\
\text { - Patients have } \\
\text { the opportunity to } \\
\text { talk with peers (eg, } \\
\text { an online support } \\
\text { forum). }\end{array}$ \\
\hline $\begin{array}{l}\text { Unit level } \\
\text { (Patients are } \\
\text { engaged at the Unit } \\
\text { level) }\end{array}$ & $\begin{array}{l}\text { - The unit supports staff in } \\
\text { patient education activities. }\end{array}$ & $\begin{array}{l}\text { - Patients provide } \\
\text { feedback via short unit- } \\
\text { specific surveys, and } \\
\text { informal interviews; this } \\
\text { information is shared with } \\
\text { staff on a consistent and } \\
\text { timely basis. } \\
\text { - Patients are invited to } \\
\text { share their experience at } \\
\text { staff meetings. } \\
\text { - Unit has a patient } \\
\text { council. }\end{array}$ & $\begin{array}{l}\text { - Patients are equal } \\
\text { members of unit } \\
\text { quality-improvement } \\
\text { councils, working } \\
\text { collaboratively with } \\
\text { their health professional } \\
\text { colleagues. } \\
\text { - Patients colead unit } \\
\text { quality improvement } \\
\text { projects. }\end{array}$ & $\begin{array}{l}\text { - Peer supporters } \\
\text { work on units to } \\
\text { support patient } \\
\text { recovery. } \\
\text { - Peer supporters } \\
\text { obtain input from } \\
\text { patients on their } \\
\text { experience and } \\
\text { outcomes. }\end{array}$ \\
\hline $\begin{array}{l}\text { ERAS initiative level } \\
\text { (Patients are } \\
\text { engaged at the } \\
\text { ERAS level) }\end{array}$ & $\begin{array}{l}\text { - The development and } \\
\text { evaluation of ERAS } \\
\text { preoperative education } \\
\text { modules are informed by what } \\
\text { patients need and want. }\end{array}$ & $\begin{array}{l}\text { - ERAS database is } \\
\text { modified to collect data } \\
\text { on PREM/PROM. } \\
\text { - Patient research } \\
\text { participants are } \\
\text { meaningfully involved } \\
\text { throughout research } \\
\text { processes. } \\
\text { - ERAS has a patient } \\
\text { council. }\end{array}$ & $\begin{array}{l}\text { - Patients are members } \\
\text { of the local and } \\
\text { international ERAS } \\
\text { project team. } \\
\text { - Patients participate } \\
\text { in the development of } \\
\text { PROM/PREM. } \\
\text { - Patients are members } \\
\text { of ERAS education } \\
\text { working groups. }\end{array}$ & $\begin{array}{l}\text { - Patients are } \\
\text { engaged as } \\
\text { researchers. } \\
\text { - Peer support is } \\
\text { built into the ERAS } \\
\text { initiative as an } \\
\text { integral component. }\end{array}$ \\
\hline
\end{tabular}

The surgical continuum across which patients are engaged extends from diagnosis to recovery.

Patients choose how they want to engage, and there is recognition that this may change over time.

The knowledge and experiential expertise that patients bring, at each of these levels, is highly valued.

PREM refers to patient-reported experience measures; PROM is patient-reported outcome measures. The cells of the matrix have been populated with some examples of how patients might be involved across the engagement continuum and at the different levels. These are not meant to be recommended activities, but are simply illustrative examples of what this kind of engagement could look like. Along the base of the matrix are three foundational elements of patient engagement: (1) the knowledge and experiential expertise that patients bring, at each of these levels, is highly valued; (2) patients choose how they want to engage and there is recognition that this may change over time; and (3) the surgical trajectory across which patients are engaged extends from diagnosis to recovery at home

ERAS, Enhanced Recovery After Surgery; PREM, patient-reported experience measures; PROM, patient-reported outcome measures.

psychological and social stressors that people undergoing serious, often life-changing surgery, may experience. Attending to these aspects of the surgical journey will contribute to better patient experiences and outcomes.

A strength of the present study is that, through all phases of research, patients were engaged as partners, and the direction of the research was driven by patient-identified priorities. As a result, we have identified a number of very practical patient concerns that, if addressed, could enhance patient experiences with ERAS (box 1). We have also developed a framework to encourage sustained patient engagement within the ERAS system (tables 2-4). A clear limitation, as with all qualitative research, is that the generalisability of the findings may be limited to the participants studied. That said, we collected data from five hospitals in Alberta and attained diversity in age, gender and community. Also, our findings are consistent with the findings of other qualitative studies of ERAS patient experiences. ${ }^{4-733}$

In conclusion, our findings suggest that patients want to be invited into the ERAS process. Patients want to be active participants in their own care. This can be 
Table 4 A mechanism for the evaluation and dissemination of outcomes at the individual care level

\begin{tabular}{|c|c|c|c|c|}
\hline & We inform patients & Patients inform us & $\begin{array}{l}\text { Patients 'co-lead' and } \\
\text { 'co-design' with us }\end{array}$ & Patients lead \\
\hline $\begin{array}{l}\text { Evaluation } \\
\text { (Examples) }\end{array}$ & $\begin{array}{l}\text { - Trivia game online } \\
\text { to assess patient } \\
\text { understanding of basic } \\
\text { ERAS guidelines and } \\
\text { principles. }\end{array}$ & $\begin{array}{l}\text { - A patient satisfaction survey to } \\
\text { evaluate education activities. } \\
\text { - An open-ended section in } \\
\text { journal/logbook for patients to } \\
\text { write about their experience, } \\
\text { which can be collected and } \\
\text { analysed using qualitative } \\
\text { methods. }\end{array}$ & $\begin{array}{l}\text { - Patients use } \\
\text { logbooks, apps or other } \\
\text { mechanisms that work } \\
\text { for them to track their } \\
\text { own recovery. } \\
\text { - Patients rate the } \\
\text { usefulness of these } \\
\text { tools. }\end{array}$ & $\begin{array}{l}\text { - Peer supporters obtain } \\
\text { input from patients on } \\
\text { their experience and } \\
\text { outcomes. }\end{array}$ \\
\hline $\begin{array}{l}\text { Dissemination } \\
\text { (Examples) }\end{array}$ & $\begin{array}{l}\text { - Game results can be } \\
\text { tabulated and presented } \\
\text { at staff meetings to } \\
\text { inform local practice of } \\
\text { patient knowledge gaps. }\end{array}$ & $\begin{array}{l}\text { - 'what's new' section on } \\
\text { the ERAS website to provide } \\
\text { feedback to patients and } \\
\text { public regarding how patient } \\
\text { involvement shapes current } \\
\text { practice. }\end{array}$ & $\begin{array}{l}\text { - Recovery tools are } \\
\text { modified based on } \\
\text { patient feedback and } \\
\text { new tools are launched } \\
\text { on the ERAS website } \\
\text { with a 'how-to' video led } \\
\text { by patients. }\end{array}$ & $\begin{array}{l}\text { - Peer supporters } \\
\text { disseminate their } \\
\text { findings at local staff } \\
\text { meetings to inform } \\
\text { current practice. }\end{array}$ \\
\hline
\end{tabular}

The cells of the matrix have been populated with some examples of how evaluation and dissemination of outcomes can be implemented at the individual care level. These are not meant to be recommended activities, but are simply illustrative examples of what this could look like. ERAS, Enhanced Recovery After Surgery.

accomplished by extending the ERAS programme to the pre- and postoperative periods, looking for opportunities to engage patients, and informing patients of the rationale for each of the ERAS elements. Patients unanimously agreed that if they had fully understood the benefits, they would pursue the ERAS protocols much more vigorously. Patients also require personalised care and appropriate adaptations within the standardised pathway. Furthermore, patient-led research provides a unique and powerful opportunity to identify issues that health professionals and policymakers may not see. This information can be used to inform development of new strategies to enhance the patient and family experiences of ERAS.

\section{Author affiliations}

${ }^{1}$ Department of Community Health Sciences, Cumming School of Medicine, University of Calgary, Calgary, Alberta, Canada

\section{Box 1 Practical recommendations to enhance the patient-orientation of Enhanced Recovery After Surgery (ERAS)}

Every ERAS protocol, and the purpose of the protocol, should be fully explained to patients both before surgery and while in-hospital, so that patients can become knowledgeable partners in their recovery.

- Extend the ERAS programme to the presurgery phase, so that patients can be ready emotionally, psychologically and physically for surgery.

- Extend the ERAS programme to the recovery period at home to avoid stressful situations for patients and families.

- Consider activating a volunteer programme where experienced patients can be available for conversations with new patients.

- ERAS, and engaging patients in ERAS, is going to look different for different patients and in different contexts (ie, there is no 'one-sizefits-all' approach). Personalised adaptations within the standardised pathway need to be considered.
${ }^{2}$ PaCER Innovates, University of Calgary, Calgary, Alberta, Canada

${ }^{3}$ Cumming School of Medicine, University of Calgary, Calgary, Alberta, Canada

${ }^{4}$ Department of Independent Health and Human Services Research and Evaluation, School of Public Health, University of Alberta, Edmonton, Alberta, Canada

${ }^{5}$ ERAS Alberta, Alberta Health Services, Calgary, Alberta, Canada

${ }^{6}$ Departments of Oncology and Obstetrics \& Gynecology, Cumming School of Medicine, University of Calgary, Calgary, Alberta, Canada

${ }^{7}$ Alberta Health Services, Strategic Clinical Networksâ,,, , Alberta, Canada

${ }^{8}$ Department of Medicine, University of Alberta, Edmonton, Alberta, Canada

Correction notice This paper has been amended since it was published Online First. Owing to a scripting error, some of the publisher names in the references were replaced with 'BMJ Publishing Group'. This only affected the full text version, not the PDF. We have since corrected these errors and the correct publishers have been inserted into the references.

Contributors All authors meet the ICMJE criteria for authorship. NM, MG, SZ, LG, GN, TW and LG were involved in the conception and design of the PaCER work. GM and $\mathrm{KG}$ conceived, designed and wrote the implementation component. MG, NM, SZ, SN and EA were involved with the acquisition, analysis and interpretation of data. CG was involved with interpretation of the data and drafted the manuscript. All authors significantly contributed to the revision of the manuscript and provided final approval of the manuscript. All authors have agreed to be accountable for all aspects of the work.

Funding This work was supported by Canadian Institutes of Health ResearchStrategy for Patient-Oriented Research (SPOR)-Patient Engagement-Collaboration Grants (grant number: 258077).

Patient consent The article does not contain identifying medical information, nor does it contain identifiable information.

Ethics approval Conjoint Research Ethics Board.

Provenance and peer review Not commissioned; externally peer reviewed.

Data sharing statement The authors do not have unpublished data to be shared.

Open Access This is an Open Access article distributed in accordance with the Creative Commons Attribution Non Commercial (CC BY-NC 4.0) license, which permits others to distribute, remix, adapt, build upon this work non-commercially, and license their derivative works on different terms, provided the original work is properly cited and the use is non-commercial. See: http://creativecommons.org/ licenses/by-nc/4.0/

(C) Article author(s) (or their employer(s) unless otherwise stated in the text of the article) 2017. All rights reserved. No commercial use is permitted unless otherwise expressly granted. 


\section{REFERENCES}

1. Ljungqvist $\mathrm{O}$, Scott $\mathrm{M}$, Fearon $\mathrm{KC}$. Enhanced recovery after surgery: a review. JAMA Surg 2017;152:292-298. Epub ahead of print.

2. Nelson G, Kiyang LN, Crumley ET, et al. Implementation of Enhanced Recovery After Surgery (ERAS) Across a Provincial Healthcare System: The ERAS Alberta Colorectal Surgery Experience. World J Surg 2016;40:1092-103.

3. Nguyen T, Chuck A, Wasylak T, et al. An economic evaluation of the enhanced Recovery after Surgery (ERAS) multi-site implementation program for colorectal surgery in Alberta. Can J Surg 2016;59:6716.

4. Blazeby JM, Soulsby M, Winstone K, et al. A qualitative evaluation of patients' experiences of an enhanced recovery programme for colorectal cancer. Colorectal Dis 2010;12:e236-e242.

5. Bernard H, Foss M. Patient experiences of enhanced recovery after surgery (ERAS). Br J Nurs 2014;23:100-6.

6. Aasa A, Hovbäck M, Berterö CM. The importance of preoperative information for patient participation in colorectal surgery care. J Clin Nurs 2013;22:1604-12.

7. Sibbern T, Bull Sellevold V, Steindal SA, et al. Patients' experiences of enhanced recovery after surgery: a systematic review of qualitative studies. J Clin Nurs 2017;26. Epub ahead of print.

8. Gustafsson UO, Hausel J, Thorell A, et al. Adherence to the enhanced recovery after surgery protocol and outcomes after colorectal cancer surgery. Arch Surg 2011;146:571-7.

9. Marlett N, Emes C. Grey matters: a Guide for Collaborative Research with seniors. Calgary, Alberta: University of Calgary Press, 2010.

10. Anderson M, McCleary KK. From passengers to co-pilots: patient roles expand. Sci Transl Med 2015;7:291fs25.

11. Domecq JP, Prutsky G, Elraiyah T, et al. Patient engagement in research: a systematic review. BMC Health Serv Res 2014;14:89.

12. Miller JL, Teare SR, Marlett N, et al. Support for living a Meaningful Life with Osteoarthritis: a Patient-to-Patient Research Study. Patient 2016:9:457-64.

13. Simmons OE, Gregory TA. Grounded action: achieving optimal and sustainable change. Forum: Qualitative Social Research 2003;4:27.

14. Teram E, Schachter CL, Stalker CA. The case for integrating grounded theory and participatory action research: empowering clients to inform professional practice. Qual Health Res 2005;15:1129-40.

15. Berger R. Now I see it, now I don?t: researcher?s position and reflexivity in qualitative research. Qualitative Research 2015;15:219-34

16. Gillard S, Simons L, Turner K, et al. Patient and public involvement in the coproduction of knowledge: reflection on the analysis of qualitative data in a mental health study. Qual Health Res 2012;22:1126-37.

17. Gill M, Bagshaw SM, McKenzie E, et al. Patient and Family MemberLed Research in the Intensive Care Unit: a novel approach to PatientCentered Research. PLoS One 2016;11:e0160947.

18. Carter N, Bryant-Lukosius D, DiCenso A, et al. The use of triangulation in qualitative research. Oncol Nurs Forum 2014;41:545-7.
19. Archer S, Montague J, Bali A. Exploring the experience of an enhanced recovery programme for gynaecological Cancer patients: a qualitative study. Perioper Med 2014;3:2.

20. Bryan S, Dukes S. The enhanced Recovery Programme for stoma patients: an audit. Br J Nurs 2010;19:831-4.

21. Fecher-Jones I, Taylor C, experience L. Lived experience, enhanced recovery and laparoscopic colonic resection. $\mathrm{Br} J$ Nurs 2015;24:223-8

22. Khan S, Wilson T, Ahmed J, et al. Quality of life and patient satisfaction with enhanced recovery protocols. Colorectal Dis 2010;12:1175-82.

23. Norlyk A, Harder I. Recovering at home: participating in a fast-track Colon cancer surgery programme. Nurs Inq 2011;18:165-73.

24. Rymaruk S, Williams J, Kurrimboccus S. Carers' perceptions of the enhanced recovery programme in colorectal surgery. J Perioper Pract 2013;23:246-50.

25. Short V, Atkinson C, Ness AR, et al. Patient experiences of perioperative nutrition within an enhanced Recovery after Surgery programme for colorectal surgery: a qualitative study. Colorectal Dis 2016;18:074-080.

26. Taylor C, Burch J. Feedback on an enhanced recovery programme for colorectal surgery. Br J Nurs 2011;20:286-90.

27. Vandrevala $T$, Senior $V$, Spring $L$, et al. 'Am I really ready to go home?': a qualitative study of patients' experience of early discharge following an enhanced recovery programme for liver resection surgery. Support Care Cancer 2016;24:3447-54.

28. Sheddy A. Handbook on Citizen Engagement: Beyond Consultation. Canadian Policy Research Network. http://cprn.org/doc.cfm?doc= 1857\&l=en (retrieved Oct 2016).

29. Kovacs Burns K, Bellows M, Eigenseher C, et al. 'Practical' resources to support patient and family engagement in healthcare decisions: a scoping review. BMC Health Serv Res 2014;14:175.

30. Carman KL, Dardess P, Maurer M, et al. Patient and family engagement: a framework for understanding the elements and developing interventions and policies. Health Aff 2013;32:223-31.

31. Alberta Innovates. Patient engagement Resources. retrieved October 2016. http://www.aihealthsolutions.ca/initiatives-partnerships/spor/ patient-engagement-platform/patient-engagement-resources/

32. International Association for Public Participation. P2 practitioner tools. retrieved October 2016. http://www.iap2.org/?page=A5

33. Lithner M, Johansson J, Andersson E, et al. Perceived information after surgery for colorectal Cancer--an explorative study. Colorectal Dis 2012;14:1340-50.

34. Graham ID, Logan J, Harrison MB, et al. Lost in knowledge translation: time for a map? J Contin Educ Health Prof 2006;26:13-24.

35. National Health Service England. Patient and public participation policy. 2015. https://www.england.nhs.uk/participation/resources/ docs/ (Retrieved March 2017)

36. Mockford C, Staniszewska S, Griffiths F, et al. The impact of patient and public involvement on UK NHS health care: a systematic review. Int J Qual Health Care 2012;24:28-38. 